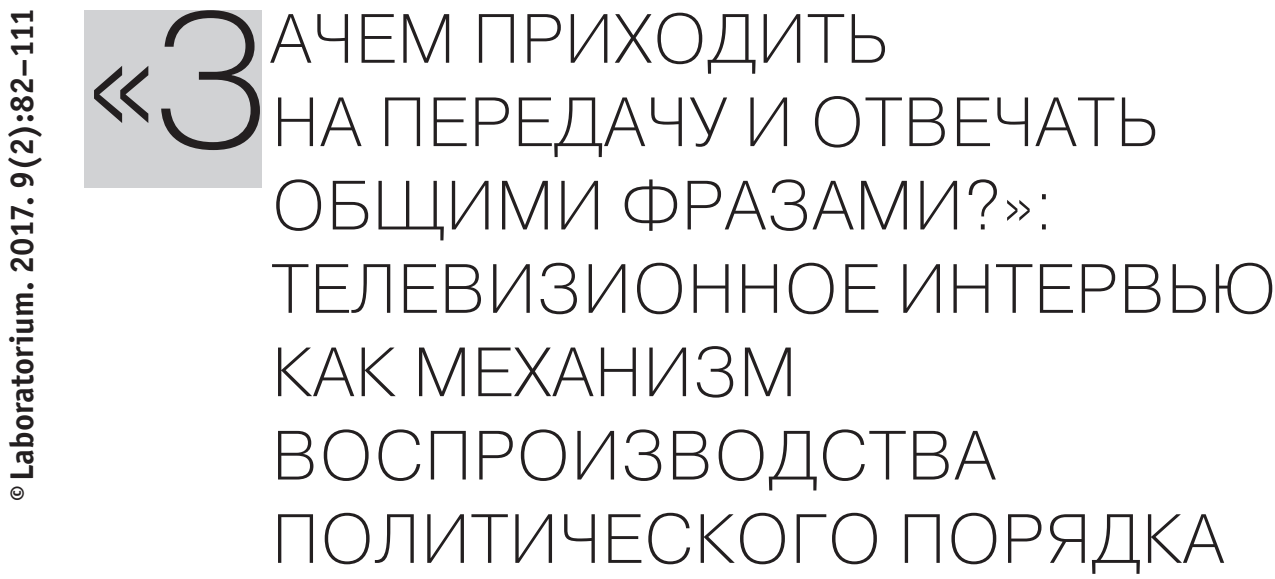

\title{
Александр Луценко
}

Александр Луценко - аспирант (PhD-программа) Междисциплинарной лаборатории по изучению рефлексивностей (LIER), Институт Марселя Мосса (IMM), Высшая школа социальных наук (EHESS) в Париже. Адрес для переписки: 10 Rue Monsieur Le Prince, 75006, Paris, France. a.loutsenko@yahoo.fr.

Автор статьи выражает благодарность редактору журнала Laboratorium Олесе Кирчик, редакторам выпуска Ивану Шупину и Франсуазе Досе, а также анонимным рецензентам за ценные советы, которые позволили значительно усовершенствовать текст рукописи. Также автор глубоко признателен журналистам и профессионалам медиа, без содействия которых настоящее исследование не было бы осуществлено.

Крупные российские бизнесмены нечасто появляются на телеэкране, тем более если они выступают не в роли экономических экспертов или ньюсмейкеров, а в качестве инсайдеров, имеющих непосредственное представление об устройстве российской системы власти. В определенный период (2011-2013 годы) недавно появившийся телеканал «Дождь» стал площадкой, на которой в публичном диалоге между журналистами и предпринимателями регулярно поднимались вопросы о взаимоотношениях между крупным бизнесом и государством. Настоящее исследование представляет телевизионное интервью в качестве элемента коллективного процесса воспроизводства политического порядка. Метод исследования включает в себя анализ видеоряда флагманской программы-интервью канала «Hard Day's Night», глубинные интервью с сотрудниками канала и совместный с ведущими программы разбор видеозаписи интервью. Основное внимание автора направлено на выявление имплицитных имперсональных правил, которые регулируют высказывания в публичном пространстве крупных предпринимателей в отношении высокопоставленных представителей государственной власти, и на оценку роли журналистов в поддержании веры в актуальность этих правил.

Ключевые слова: телевизионное интервью; крупные бизнесмены; журналисты; договор вовлеченности; производство фактов; правила; невербальные реакции; политический порядок 
Весной 2012 года гостем программы-интервью «Hard Day's Night» на телеканале «Дождь» ${ }^{1}$ стал известный представитель российской бизнес-элиты. В середине программы внизу экрана появился комментарий одного из зрителей: «Зачем приходить на передачу и отвечать общими фразами?..»². Если сопоставить попавшее в эфир высказывание с другими комментариями루, которые аудитория оставляет на Youtube, в Facebook и Twitter, окажется, что подобная оценка достаточно типична для интервью с крупными предпринимателями на этом канале ${ }^{4}$. С появлением (благодаря соцсетям и другим интернет-площадкам) новых способов для высказывания мнений и оценок зритель, который в течение долгого времени имел лишь ограниченные возможности для публичного выражения своего отношения к происходящему на телеэкране, наконец получил право голоса. Вместе с этим возник новый стимул для размышления над вопросом, который давно беспокоит как профессионалов медиа, так и социологов: что происходит, когда зритель смотрит телепрограмму? В контексте телевизионных интервью этот вопрос встает особенно остро, потому что, являясь редким моментом представления публике облеченных властью персон ${ }^{5}$, телеинтервью становятся важным элементом процесса поддержания (а возможно, и переопределения) политического порядка (Ekström 2001; Clayman et al. 2007). Характеризуя политический порядок в России с точки зрения отношений между крупным бизнесом и властью, принято говорить о том, что с начала 2000-х годов крупные бизнесмены оказались в подчиненном положении по отношению к высокопоставленным представителям го-

1 Частный телевизионный канал, который начал вещание в 2010 году. На момент выхода интервью (весна 2012 года) был доступен по кабельным и спутниковым сетям, а также в интернете. Аудитория телеканала в классических телеприемниках в тот момент составляла около 8 млн. человек в месяц (по данным TNS Russia); интернет-аудитория - около 1,5 млн. уникальных пользователей в месяц (по данным Google Analytics). Канал отличается независимой редакционной политикой и всесторонним освещением резонансных общественно-политических событий, которые по каким-либо причинам могут быть не полностью или вовсе не освещены государственными федеральными телеканалами (акции протеста, уголовные дела, громкие журналистские расследования). Руководители телеканала «Дождь» определяют свою аудиторию как образованную и успешную, разочаровавшуюся в классическом государственном телевидении (Интервью с директором канала, 19 мая 2016 г.).

2 Здесь и далее при цитировании: орфография и пунктуация оригинала сохранены.

${ }^{3}$ Среди них, например, можно встретить следующие: «...вот это у него “фильтр базара". Боится слова сказать лишнего, каждый предлог фильтрует. Если так боится за шкуру, что тогда приходил сюда?..», «Казалось бы долларовый миллиардер огромного бизнеса на разговоре с журналистом ведет себя так, будто за лишнюю сказанную фразу все что он создавал 20 лет будет стерто», «0чень тяжело его слушать постоянно куда-то скользит...».

4 За последние 5 лет в программе «Hard Day's Night» и в других похожих программах-интервью телеканала побывало более десяти гостей, постоянно входящих в список ста богатейших бизнесменов России по версии журнала «Форбс», что больше, чем на любом российском федеральном канале, за исключением новостного телеканала «Россия 24».

${ }^{5}$ Строго говоря, в качестве интервьюируемых могут выступать и вполне обычные люди. См., например, «интервью с очевидцем» или «экспертное интервью» (Montgomery 2008; Ekström and Kroon Lundell 2009). В настоящей работе эти типы интервью не рассматриваются. 
сударственной власти ${ }^{6}$ В настоящем исследовании на примере интервью с крупным предпринимателем в программе «Hard Day's Night» будет показано, каким образом телевизионное интервью может выступать в качестве «актуализатора» этих отношений.

Сталкиваясь с активной и требовательной реакцией зрителя (подобной той, что была продемонстрирована выше), исследователь ощущает некоторую ограниченность моделей производства смысла и негоциации прочтения, предложенных, например, в работах Стюарта Холла (Hall [1973] 1980) и Дэвида Морли (Morley 1980). Даниэль Дайан (Dayan 1992) призывает к преодолению диады «текст - читатель», с тем чтобы перестать мыслить программу и зрителя изолированно, как две отдельные сущности. Контакт зрителя с программой следует понимать не в терминах отстраненного производства смысла текста, а в терминах вовлеченности в роль. К такому выводу Дайан приходит в результате совместного с Элиаху Кацем изучения телевизионных трансляций церемониальных событий, которые они называют «медиасобытиями»: «Медиасобытия требуют не только согласия зрителя, они требуют его активной вовлеченности» ${ }^{7}$ (Dayan and Katz 1992:120). «Суть вовлеченности, - уточняет Дэниэл Сефай, - в меньшей степени состоит в производстве содержания конкретных программ и в большей степени - в конфигурировании ролей рецепции (rôles de réception)» (Cefaï and Pasquier 2003:45).

Авторы, рассуждающие в терминах вовлеченности, опираются на заимствованный у Ирвинга Гофмана концепт «фрейм участия» (participation framework). Считается, что программа формирует некоторый фрейм участия, где зрителю тоже отведена определенная роль. Это не предполагает, однако, никакого автоматизма в принятии роли и степени вовлеченности. Соня Ливингстон и Питер Лант, говоря о ток-шоу, объясняют, что для зрителя «различные фреймы участия легитимны, и между текстом и зрителем открыт процесс негоциации» (Livingstone and Lunt 1994:68). Но речь идет уже не о негоциации прочтения, как в моделях Холла или Морли, упомянутых выше, а о негоциации формы участия, которую принимает зритель в событии, производимом программой. Понятие негоциации предполагает, тем не менее, что программой может быть задана некоторая преференциальная форма участия. Ливингстон и Лант вводят понятие «ориентира» (cue), чтобы показать, каким образом программа может подсказывать зрителю форму вовлеченности: «Программа предлагает разные ориентиры посредством ее темы, степени открытости или закрытости, критериев оценки» (68). Отношения между программой и зрителем в результате можно понимать как некий договор, в том плане что программой предлагается некоторая базовая форма вовлеченности, предполага-

${ }^{6}$ Мириам Дезер говорит, например, о «юридической уязвимости» российского крупного бизнеса, делающей его зависимым от расположения государства (Désert 2010; см. также Guriev and Rachinsky 2005). Яков Паппэ и Яна Галухина пишут по этому поводу: «исполнительная власть (президентская вертикаль), установив контроль над законодательной и судебной, получила возможность выстраивать свои отношения с бизнесом исключительно с позиции силы, не считаясь с его интересами» (Паппэ и Галухина 2009:159).

7 Здесь и далее в тексте все цитаты из англо- и франкоязычных работ даны в переводе автора настоящей статьи. 
ющая определенные обязательства как для одной, так и для другой стороны, выполнение которых не является гарантированным и является предметом переговоров. Согласно Дайану, само понятие жанра программы подразумевает договор, который затрагивает целый комплекс характеристик, начиная от нарративного формата и степени открытости или закрытости высказываний и заканчивая критериями достоверности программы (Dayan 1992).

Подход в терминах договора вовлеченности может оказаться полезным при изучении затронутого в настоящей статье феномена. Комментарий зрителя, приведенный в начале текста, как и многие другие подобные комментарии, сигнализирует о некоторой проблеме вовлеченности. Если продолжать придерживаться юридической метафоры, то парадоксальность ситуации, обозначаемой зрителями, состоит в том, что в интервью с крупными предпринимателями предлагаемый программой договор, который зрители принимают, в действительности систематически не выполняется по вине гостя программы. Целью настоящего исследования является попытка понять, почему у зрителей может складываться подобное впечатление о выступлении интервьюируемого и какое отношение эта ситуация может иметь к процессу поддержания политического порядка в сфере взаимоотношений между крупным бизнесом и властью. Зрители склонны связывать проблему выступления на интервью с личными особенностями поведения гостя программы, однако наше исследование предложит социологический подход, принимающий во внимание локальный интеракционный и общий социальный контексты действий интервьюируемого.

Следует сразу пояснить, что социальный контекст деятельности интервьюируемого будет интересовать нас в той форме, в которой он проявлялся и воспроизводился в ситуации интервью действиями участников интеракции и их интерпретационной деятельностью вокруг этой интеракции. Поэтому при анализе данных мы будем стремиться максимально абстрагироваться как от собственных представлений о социальной структуре, так и от представлений, транслируемых в академической литературе, посвященной крупному бизнесу и его взаимоотношениям с государством, с тем чтобы в полной мере обратить внимание на то, каким образом эта социальная структура осмысляется самими акторами и становится основанием для их действий. В силу того, что полный доступ был обеспечен только к журналистам, фигура крупного бизнесмена будет присутствовать в работе лишь косвенно, через его действия, наблюдаемые в конкретной ситуации интеракции, и через суждения, которые высказывали о нем журналисты. Основной акцент в статье будет сделан на журналистской деятельности в процессе интервью.

Применяемый в работе подход предполагает в первую очередь уточнение условий договора, предлагаемого передачей. Мы изучим фрейм участия программы и постараемся определить заданные ею роли и обязательства участников. Материалом для этой части послужит анализ видео- и аудиоряда программы, а также социологические интервью с сотрудниками канала, так или иначе связанными с производством программы. Далее будет предпринята попытка определить, что мешает интервьюируемому воплощать ту роль, которую от него ожидают зрители. Будет показано, что выступление гостя на интервью происходит на фоне процесса 
установления фактов, связанных с профессиональной деятельностью интервьюируемого, в контексте взаимодействия с журналистами. Мы сосредоточим внимание на изучении организации интеракции между интервьюируемым и интервьюерами, детально рассмотрим один из фрагментов программы, используя особый метод, состоящий в разборе видеозаписи интервью совместно с участвовавшими в нем журналистами.

\section{ФРЕЙМ УЧАСТИЯ ПРОГРАММЫ И ОБЯЗАТЕЛЬСТВА УЧАСТНИКОВ}

Постоянство ролевой структуры на протяжении всей программы не гарантировано и является результатом выполнения участниками своих ролей, или, говоря иначе, условий договора, начальные положения которого могут быть при этом установлены. Ален Бове и Седрик Терци отмечают, что «описывать кадр - это не значит восстанавливать в языковой форме то, что происходит на экране. Напротив, это значит признавать наличие конфигурации, то есть проводить различие между тем, что составляет “фон" картинки, и тем, что выделяется на нем в качестве “фигур"» (Bovet and Terzi 2011:233). Нашей задачей, таким образом, станет не исчерпывающее описание всего, что происходит в передаче, а выявление конфигурации программы, связанной с замыслом, который закладывали в нее ее создатели.

Программа «Hard Day's Night» появилась на экране в мае 2011 года, она выходит в эфир еженедельно по вторникам после 22 часов. Это флагманская программа-интервью канала. Сотрудники «Дождя» определяют жанр программы как «портретное интервью», понимая под этим определением в основном то, что темы интервью не ограничены текущими новостными поводами (хотя им отводится существенное место), а интерес журналистов вызывают не только деятельность, но и личность гостя. Обратимся к рассмотрению видеоряда программы, который мы дополним комментариями, полученными от сотрудников канала. В центре нашего внимания будет один конкретный выпуск программы, на который отреагировал зритель, но сказанное в целом применимо для любого выпуска с участием крупного предпринимателя.

Заставка программы представляет собой сцены подготовки интервьюеров и прибытия гостя программы. Журналисты и гость все время изображены по отдельности, в разных сценах, что с самого начала создает ощущение если не конфликта, то некоторой напряженности между сторонами. Интервьюеры в строгих костюмах, автомобиль представительского класса, черно-белая цветовая гамма ролика, все эти детали заставки демонстрируют намерение создателей программы подчеркнуть не развлекательный, а наоборот, строгий и в некоторой степени официальный характер мероприятия. Название программы «Hard Day's Night» содержит отсылку к профессиональной стороне деятельности интервьюируемого: для гостя, силуэт которого появляется в последнем кадре заставки - фигура с пиджаком, закинутым на плечо, словно гость приехал на программу после важной встречи, - предстоящий разговор должен стать еще одним непростым событием его трудного дня. 
Заставка сменяется кадрами из студии, оформленной в темно-серых тонах, демонстрирующей полное отсутствие какого-либо декора, в помещении только грубые кованые стулья и стол. Продюсер программы в своем интервью так объясняет строгий стиль:

Есть специфика, что все ведущие в строгих костюмах... Я стремлюсь, по крайней мере, к этому. Это статусность. Она может быть совершенно визуальной. Строгость и статусность. Настроенность на серьезный разговор, а не вечерний late-night show какой-то там. «Вечерность» и строгость передает и интерьер, декорация (Интервью с продюсером программы, 31 мая 2016 г.).

Аскетичный антураж не только подчеркивает строгость и серьезность мероприятия, он не позволяет зрителю отвлечься и приковывает все внимание к гостю программы. Камера то медленно скользит по студии, не теряя при этом гостя из вида, то выхватывает крупный план одного из участников интервью. Интервьюируемый весь на виду. Он сидит на непропорционально высоком стуле, возвышаясь над пространством студии (похожие стулья и у журналистов). И даже узкий вытянутый стол, вокруг которого расположены участники интервью, имеет прозрачную столешницу, что не позволяет гостю программы утаить от внимания аудитории ни одного своего движения.

Исследователь: Как можно охарактеризовать интерьер? Кто-то говорит, что это похоже на инквизицию, некоторую форма суда.

Продюсер: Ну, конечно, мы пытаемся... Мы не говорим, что «сейчас вы будете допрошены», но, определенно, и железные стулья (а это не кресла, а именно стулья), и все остальное работает на то, чтобы у гостя было ощущение, что это серьезный разговор по существу. Ну, то есть, что важно сейчас сказать, ответить на вопросы. Примерно такого настроя мы добиваемся (Интервью с продюсером программы, 31 мая 2016 г.).

Неудобные стулья, максимальная доступность обзору, антураж, фокусирующий внимание на фигуре гостя, демонстрируют направленность интервью на выявление, вскрытие того, о чем гость не стал бы рассказывать спонтанно. «У нас есть час, для того чтобы обсудить абсолютно разные вопросы, связанные так или иначе с вашей деятельностью», - объявляет ведущий, предваряя первый вопрос, и это дает понять, что именно профессиональный статус гостя будет в центре внимания интервьюеров. Их пятеро: по двое вдоль длинных сторон стола (с правой и левой стороны от гостя) и один напротив - это ведущий и модератор программы. Расширенный (по сравнению с обычной ситуацией интервью) состав интервьюеров является главной особенностью программы. Из них постоянен лишь ведущий, остальные (трое журналистов из пула канала и один из профильного СМИ) подбираются под каждого конкретного гостя в зависимости от его сферы деятельности. Такой формат был придуман генеральным директором и создателем канала Натальей Синдеевой: 
Это возможность усилить компетенцию, когда ты берешь интервью. Почему в «Hard Day's Night» должны приходить «топы»? Потому что когда к тебе приходит условный Вексельберг, то один журналист [...], у него нет семи пядей во лбу, чтобы охватить весь спектр и быть компетентным. А таким образом ты одновременно разных можешь брать журналистов (Интервью с директором канала, 19 мая 2016 г.).

Участие сразу нескольких профильных журналистов позволяет выстраивать с интервьюируемым разговор «на равных» и преодолеть разницу в степени информированности и понимании обсуждаемой ситуации, которая может возникнуть между представителем экономической или политической элиты и отдельно взятым журналистом, пусть и специализирующимся в той же сфере, в которой занят гость. Изучение регламента программы поможет понять, каким образом реализуется подобная коллективная компетенция. Описание программы на сайте канала гласит: «Каждый выпуск “Hard Day's Night” - это новый гость, это самые интересные политики и бизнесмены. Мы не устраиваем гостю пресс-конференцию - мы общаемся на темы, которые интересны ему и важны нам». Действительно, несмотря на то, что журналистов много, они действуют не каждый сам по себе, как в случае пресс-конференции, а единым фронтом. Программе предшествует «летучка», на которой интервьюеры совместно определяют список и порядок тем (обычно в программе затрагивается 4-5 таких тем), формулируют вводный вопрос для каждой темы и решают, кто будет задавать его гостю. Несмотря на то, что этот вводный вопрос задает один конкретный интервьюер, далее к обсуждению темы с дополнительными вопросами и возражениями подключаются остальные журналисты - в результате в опросе гостя участвуют все интервьюеры (ведущий-модератор старается при этом следить за тем, чтобы участники интервью говорили по очереди). Такая форма организации интервью, направленная на то, чтобы жестко контролировать ответы интервьюируемого, не давая ему возможности перехватывать инициативу и уводить разговор в сторону, говорит о нацеленности журналистов на получение точной информации по заранее продуманным вопросам.

В начале программы ведущий смотрит в камеру, представляется, приветствует зрителей программы и тем самым делает их, говоря языком Гофмана, «ратифицированными участниками» интеракции. Затем ведущий представляет гостя, называет его должность и компанию, что дает зрителям ориентиры для категоризации и оценки. И только представив аудитории других интервьюеров, он поворачивается к гостю, приветствует его и переходит к вопросам. Какие отношения должны устанавливаться между зрителем и гостем по замыслу создателей программы? Для ответа на этот вопрос полезно обратиться к тому, как ведущий программы определяет принципы отбора гостей в передачу. Это позволит понять, какое место в их ряду отведено крупным бизнесменам.

Здесь бизнесменов нельзя отделить от политиков. Потому что идея программы изначально заключалась в том, что туда приглашают, условно говоря, «топ». То есть эта программа [...], ее идеология заключается в том, что высокопоставленные политики [...], крупные бизнесмены и какие-то, условно го- 
воря, «совести нации» (но в меньшей степени, так как в большей степени это все-таки элита бизнеса и политики) разговаривают с журналистами, которые профессионально занимаются этой тематикой (Интервью с ведущим программы, 14 сентября 2015 г.).

Ведущий использует слово «топ» для общей идентификации гостей (обратим внимание на то, что тот же самый термин был использован директором канала см. предыдущую цитату из интервью). Это слово, которому в обыденном языке соответствует понятие «верхушка», отсылает не только к персональному положению приглашенного, но и в некоторой степени к структуре всего коллективного тела, в рамках которого это положение реализовано. Несмотря на то, что гости программы заняты в разных профессиональных сферах (которые условно можно обозначить как «политика», «бизнес» и «культура»), можно выявить некоторое общее качество, придающее смысл их присутствию в программе. То, что именно фигура политика (ср. высказывание из интервью: «здесь бизнесменов нельзя отделить от политиков») в данном случае выступает в качестве модели, позволяющей ведущему определить специфику роли, в которой в программе выступают бизнесмены, указывает на некоторую идею «представления других», заложенную в восприятие крупных бизнесменов и в целом всех гостей программы. Эти наблюдения позволяют наметить контуры отношений, связывающих зрителя и интервьюируемого в данной программе. Эти отношения содержат некоторые черты того, что Люк Болтански и Лоран Тевено ([1991] 2013) понимают под отношением «представления» или «воплощения», говоря о том, что «великие» ${ }^{8}$ всегда представляют «малых». Зрителю как малой части коллективного тела явлен тот, кто в силу своей особой социальной роли - «великого» (в терминологии Болтански и Тевено), - до известной степени воплощает или включает в себя это тело целиком.

Обратимся теперь к тому, как ведущий определяет цель интервью. Иными словами - к тому, что интервью должно продемонстрировать зрителю.

Тематика вопросов - она определялась... Там как бы было... Если можно вопросы поделить на две части... Одна часть - это актуальность. Что-то происходит с чем-то. Второе - это личность человека, потому что интересно понять, что собой представляет тот или иной человек, которого зрители обычно воспринимают исключительно как функцию (Интервью с ведущим программы, 14 сентября 2015 г.).

«Функция», отсылающая к социальной роли, определенная выше как имеющая некоторые черты воплощения или представления других, не исчерпывает

${ }^{8}$ Согласно Болтански и Тевено, «величие - это способность выражать, воплощать, включать в себя других или же представлять их в своем лице. [...]. В каждом мире величие людей соотносится с их умением владеть общими формами. Это умение проявляется, в частности, в способности людей высказывать общие, достоверные, истинные суждения. Как говорил Ж. Боссюэ, “великим людям свойственны великие мысли”. И только “великие" обладают в полной мере когнитивной способностью к обобщению» ([1991] 2013:211). 
сущности интервьюируемого. У него есть еще одна сторона, обозначаемая ведущим как «личность», которая может пониматься как физическое воплощение этой социальной роли. Раскрытие или проявление стоящей за социальной ролью «личности», второстепенной или недоступной для наблюдения зрителем в большинстве других социальных ситуаций, является для журналистов одной из важных целей интервью (ср. цитату из интервью выше). Иными словами, интервью представляет собой публичную ситуацию, при которой присваивание социальной роли конкретному лицу перестает быть беспроблемным, две эти сущности на время разъединяются, и соответствие лица («личности») присваиваемой роли перестает быть само собой разумеющимся. Зритель, которому теперь явлена не только присвоенная интервьюируемому социальная роль «великого», но и проявленная благодаря вопросам интервьюеров «личность» последнего (его реальные поступки, а не громкий статус), получает возможность наглядно оценить соответствие одного другому. Интервью при этом превращается для интервьюируемого в определенного рода публичную проверку или испытание ${ }^{9}$, во время которого его претензия на воплощение социальной роли должна быть подтверждена перед лицом аудитории, что придает последней некие судейские функции.

Релевантность вопроса об искренности интервьюируемого, по поводу которой зрители высказывают свои критические комментарии, в свете этих пояснений становится более понятной. В отличие от других форм испытания как процесса оценивания, например, суда, на котором суждение принимающих решение о «виновности» или «невиновности» лица базируется на целой совокупности оснований (свидетельские показания, материальные улики и т. д.), в форме испытания, которую представляет собой публичное телевизионное интервью, суждение основывается главным образом на том, что говорит интервьюируемый. Поэтому особое внимание уделяется процедурам, позволяющим квалифицировать, насколько то, что говорится, в полной и неискаженной форме отражает действительность. Представляется, что именно поэтому различные формы «недоговаривания», ухода от ответа и другие проявления того, что исследователи интервью называют «отсутствием кооперации» (uncooperativeness), воспринимаются как ошибки интервьюируемых (Fetzeret and Weizman 2006; Hutchby 2006). Как иронично замечает Стивен Клэймэн, «в то время как американские граждане имеют охраняемое конституцией право хранить молчание на полицейском допросе, так что молчание не может быть инкриминировано им в суде, публичные фигуры лишены такой защиты на суде общественного мнения, которым является журналистское интервью»

\footnotetext{
${ }^{9}$ Понятие «испытание» (épreuve) является центральным для французской прагматической социологии, один из постулатов которой - относительная недетерминированность социального мира, выражающаяся в том, что любое распределение отношений власти содержит потенциал для пересмотра: «Власть не существует вне испытаний, в которых она проявляется» (Barthe et al. 2013:194). Испытание - а вся социальная жизнь представлена как серия испытаний разного масштаба - является моментом, когда прежнее положение дел проверяется на прочность. Вне зависимости от исхода каждое испытание приводит к некоему новому состоянию социального мира, которое продержится до нового испытания.
} 
(Clayman 2001:405). Недоумение зрителя, выраженное в комментарии, таким образом, может быть связано с тем, что, согласившись на интервью (и тем самым дав добровольное согласие предстать перед судом общественного мнения), интервьюируемый не демонстрирует достаточной искренности, необходимой для вынесения вердикта. Отсутствие искренности воспринимается зрителем как осознанный выбор интервьюируемого и как объективная черта его действий.

Итак, первоначальный замысел программы можно схематично представить как публичное, ориентированное на зрителя выявление журналистами фактов, связанных с профессиональной деятельностью гостя, на основании которых аудитория производит оценку соответствия его той социальной роли, которую он воплощает.

\section{МЕТОДЫ ПРОИЗВОДСТВА ФАКТОВ В ПРОЦЕССЕ ИНТЕРВЬЮ}

Многие исследователи указывают на то, что в контексте журналистской деятельности факты являются не зеркальным отражением действительности, а продуктом социальной работы, о которой принято говорить в терминах «производства» (Molotch and Lester 1974; Tuchman 1978; Gans 1979). Для Гэй Такман понятие журналистского факта тесно связано с методами получения информации: «Под фактами я понимаю релевантную информацию, собранную при помощи профессионально утвержденных методов, оговаривающих соотношение между тем, что известно, и тем, как это стало известно» (Tuchman 1978:82). В современной журналистике эти методы в большинстве случаев так или иначе связаны с контактами с источником (Schudson 1994; Chupin and Nollet 2006; Kaciaf 2007; Legavre 2011). Леон Сигал подчеркивает, что «новости - это не то, что случилось, а то, что кто-то рассказал о том, что случилось» (Sigal 1986:15).

Обычно контакты с источниками используются для сбора информации, которую журналисты затем публикуют, применяя дополнительно различные способы ее «упаковывания» и представления. Эти способы связаны с обстоятельствами получения информации от источников. В отдельных случаях, например, информация не может быть опубликована в таком виде, в котором она была получена, но может быть использована журналистами для общего понимания ситуации, в иных ситуациях она подлежит публикации без указания источника и т. д. (Sigal 1973). Основная особенность публичного интервью состоит в том, что в рамках такой формы интеракции контакт журналиста с источником приобретает характер новости сам по себе. Клэймэн и Херитейдж поясняют, что “"новость” в новостных интервью состоит [...] в повседневных интеракционных транзакциях между журналистами и их источниками» (Clayman and Heritage 2002:11). Иными словами, источник не только предоставляет информацию, но и сам «публикует» ее в контексте вопросно-ответной интеракции особого рода (Greatbatch 1988).

0 том, как именно продуцируются в процессе интервью факты, сказано пока немного. В качестве основного рассматривается метод прямого проговаривания, когда интервьюируемый вербализует некоторую информацию или словесно подтверждает предположения журналистов. Так, внимание исследователей, изучаю- 
щих интервью в рамках конверсационного анализа, сосредоточено на рассмотрении находящихся на вооружении у журналистов средств для принуждения интервьюируемого к производству прямого ответа (Clayman 2001; Clayman and Heritage 2002), а также применяемых интервьюируемыми техник для того, чтобы от подобного ответа уходить (Harris 1991; Bull and Mayer 1993). Далее мы покажем, что прямое проговаривание интервьюируемым некоторой информации не является единственным методом производства фактов в контексте публичного интервью. Это позволит усложнить распространенную в социологии медиа идею о том, что источники жестко контролируют процесс производства новостей. Согласно авторам книги «Mediating the Message» (Shoemaker and Reese 1996), наиболее очевидной формой влияния источника на журналиста является ситуация, когда источник замалчивает информацию или намеренно ее искажает. Мы постараемся показать, что в контексте публичного интервью даже такое поведение ньюсмейкера не исключает возможности производства фактов.

Прежде чем мы перейдем к изучению особенностей производства фактов в процессе интервью, необходимо описать используемый метод исследования. Дон Циммерман (Zimmerman 1974) обращает внимание на то, что процесс производства фактов является практическим осуществлением. Его изучение невозможно без понимания фоновых предпосылок, на которых базируются действия компетентных акторов, участвующих в этом производстве. Исследователь телевизионных интервью имеет возможность обратиться к видеозаписи телевизионной программы, позволяющей восстановить некоторые черты исходной ситуации взаимодействия и действий участников. Однако профессиональная компетенция гостей программы и журналистов, которые ежедневно контактируют с представителями политической и экономической элиты, значительно отличается от познаний обычных зрителей (к которым можно причислить и исследователя). Эрик Невё неоднократно указывал на практическую проблему, с которой сталкиваются журналисты, обладающие экспертным знанием, при переводе их взаимодействий с политиками на понятный обывателю язык в рамках телевизионной программы. Говоря о стоящей перед журналистами необходимости «вульгаризировать» информацию, Невё обращает внимание на эпистемическую дистанцию, которая разделяет ньюсмейкеров и экспертов-журналистов - с одной стороны, и аудиторию - с другой (Neveu $1989,1995)$. В контексте телевизионных интервью эта проблема проявляется еще и в том, что производимые в этой ситуации действия участников не всегда полностью прозрачны для менее компетентных наблюдателей. На практике в процессе «праздного» просмотра интервью подобная непрозрачность редко становится проблемой, но в случае, когда задачей исследователя является наиболее подробное восстановление деталей интеракции, необходима более глубокая степень эксплицируемости действий, что требует применения дополнительных (помимо анализа видеозаписи) методов исследования. Такая эксплицируемость может быть достигнута на социологическом интервью с журналистами. Однако здесь возникает проблема, связанная с потерей наблюдаемости конкретных действий участников интервью. Угроза заключается в том, что респондент передаст исследователю лишь свои общие представления об организации интервью и идеологи- 
ческие обоснования своей деятельности, тогда как детальное рассмотрение случая будет невозможно. Говоря языком Роберта Эмерсона (Emerson 1981), исследователь рискует получить от респондентов «перспективу о действии» (perspective of action), а не «перспективу в действии» (perspective in action). Искомый метод, таким образом, должен давать возможность синхронной адресации и к непосредственно наблюдаемым, вписанным в контекст действиям акторов, и к подробным описаниям и разъяснениям этих действий в речи. Решением стало использование видеозаписи телепрограммы и обсуждение ее во время исследовательских интервью с участвовавшими в программе журналистами. В процессе такого совместного аналитического просмотра программы можно остановить воспроизведение или повторно посмотреть интересующий эпизод. Такой метод дает возможность наблюдать действия участников телеинтервью так, как они видимы зрителю, и при этом получать о них развернутые пояснения от журналистов ${ }^{10}$.

Перейдем теперь непосредственно к изучению процесса производства фактов на интервью. Мы сосредоточим внимание на завершающей части этого процесса, на самой интеракции в студии. Вопросы, связанные с тем, каким образом журналистами была получена предварительная информация о рассматриваемых событиях, и почему именно они были отобраны в качестве тем для вопросов на интервью, в настоящей статье рассматриваться не будут ${ }^{11}$.

Вернемся к тому интервью, которое упоминалось в самом начале и к которому относится комментарий зрителя. Мы выберем из него фрагмент, где обсуждается некое конкретное событие, к которому интервьюируемый имеет прямое отношение и о котором он, соответственно, должен иметь непосредственное представление. Таков, например, фрагмент, в котором обсуждались недавние (на момент интервью) события, связанные с давлением на нефтяную компанию, находящуюся под контролем гостя программы. Целью журналистов здесь было выявление обстоятельств этого давления. Для удобства анализа фрагмент телеинтервью будет разбит на четыре эпизода. За каждым эпизодом будет следовать его разбор с одним из двух опрошенных интервьюеров.

Эпизод 1. Первый эпизод начинается с того, что ведущий программы передает слово одному из интервьюеров и приглашает его задать следующий вопрос, обозначая тем самым переход к новой теме. Ниже приведен соответствующий эпизоду отрывок из транскрипта телеинтервью:

Ведущий: Пожалуйста, Александр.

\footnotetext{
${ }^{10}$ Описанный метод применялся в социологических интервью с двумя журналистами, участвовавшими в программе (интервью были проведены в октябре 2015 года). Социологическое интервью с ведущим программы, фрагменты из которого приведены в первой части статьи, проводилось без просмотра видеозаписи программы.

${ }^{11}$ Ответ на эти вопросы потребовал бы рассмотрения более широкого контекста деятельности журналистов, что не входило в задачи настоящего исследования. Некоторые попытки осветить эти вопросы предпринимались, например, в следующих работах: Schlesinger (1978); Gans (1979); Shoemaker and Reese (1996).
} 
Интервьюер 1: Я хочу перейти к другой истории взаимоотношения с государством. [...] Ваша компания «Башнефть», которая имела достаточно истощенные месторождения, получила огромное совершенно месторождение Треббса и Титова [...]. И что мы наблюдаем в последние дни? Сначала депутат от ЛДПР подает запрос: а не разобраться ли, как это «Башнефть» получила Треббса и Титова? Затем появляется миноритарный акционер, который вообще подает иск о том, чтобы пересмотреть это. На ваш взгляд, ведь не бывает такого в истории корпорации, чтобы люди, так называемые борцы за правду, а не за выгоду, из акционеров - они вдруг вот так кучно начинают появляться...

B $^{12}$ : Ну, понятен вопрос, да.

Интервьюируемый: Понимаете...

ИР 1: Кто за этим стоит?

Учитывая, что просмотр этого эпизода открывал совместный разбор видеозаписи с респондентом А, казалось интересным выяснить, имеет ли журналист какие-либо общие предварительные ожидания по поводу того, как интервьюируемый будет отвечать. Для этого проигрывание видеозаписи было приостановлено в тот момент, когда вводный вопрос уже прозвучал, но ответа интервьюируемого еще не последовало. Ниже приведен отрывок из транскрипта исследовательского интервью с респондентом А, соответствующий обсуждению рассматриваемого эпизода:

Исследователь: Как Вы думаете, как интервьюируемый ответит на этот вопрос? Пока мы не услышали ответ.

Респондент А: Вообще он очень осторожный человек, очень. От этого проистекает в том числе и то, что он в добрых отношениях со всеми и, скажем так, с государством. И даже потеряв «Башнефть», он не озлоблялся, и как только он был выпущен из-под домашнего ареста, Путин его тут же позвал к себе. То есть человек вел себя по правилам этой тусовки, вел себя правильно.

И: А что за правила этой тусовки?

PA: Ну, в том числе - не начинать наезжать.

И: На кого?

PA: На возможных виновников своих... Ну, это как история с Иовом библейская, который кричал «Господи, за что?». В ситуации российских отношений с властью вот этого не надо делать.

12 Здесь и далее в транскрипте телеинтервью мы будем обозначать сокращенно ведущего, интервьюируемого и интервьюеров: В (ведущий), иЙ (интервьюируемый), ИР1 (интервьюер 1), ИР2 (интервьюер 2) и т. д. В транскрипте исследовательских интервью мы будем обозначать сокращенно исследователя и респондентов: И (исследователь), РА (респондент А), РБ (респондент Б). В целях сохранения анонимности респондентов мы не будем указывать, какие реплики принадлежали им в исходном телеинтервью. В тексте примеров уточнения автора будут приводиться в квадратных скобках. 
Обратим внимание на то, что вместо того, чтобы говорить непосредственно о предполагаемом ответе интервьюируемого (как того требовал вопрос исследователя), респондент считает нужным отметить особую осторожность гостя. Обосновывая свою оценку, журналист приводит в пример ситуацию, когда после выхода из-под домашнего ареста бизнесмен был приглашен на прием к президенту. По мнению журналиста, этот эпизод свидетельствует о том, что, даже находясь в затруднительной ситуации, предприниматель не допустил действий, которые могли бы испортить его отношения с высокопоставленными представителями власти. Респондент заключает, что интервьюируемый «вел себя по правилам этой тусовки», обнаруживая тем самым наличие некоторых актуальных для крупных предпринимателей ${ }^{13}$ негласных правил, которые (судя по тому, что отсылка к этим правилам возникает в контексте оценки предполагаемого ответа интервьюируемого) затрагивают возможность их публичных высказываний. Далее одно из правил получает более подробное определение, респондент формулирует его как «не наезжать на виновников», имея в виду запрет на публичное обличение связанных с властью лиц.

Первый вывод, который может быть сделан на основе разбора интеракции, состоит в том, что производство фактов на интервью не гарантируется одним лишь тем, что интервьюируемый обладает информацией, касающейся восстанавливаемого журналистами события. Важно также, чтобы эта информация могла быть 0звучена публично (могла быть «публицизирована»). Эта возможность регулируется некоторым набором негласных правил, действующих для крупных предпринимателей в публичном пространстве.

Эпизод 2. Обратимся к следующему эпизоду телеинтервью. Вводный вопрос задан, и интервьюируемый приступает к ответу. Ниже приведен соответствующий отрывок из транскрипта программы:

Интервьюируемый: ...я вам отвечаю...

Интервьюер 2: Это накат вообще на «Башнефть»?

й̆: Я вам отвечаю просто. Бизнес... Бизнес - это минное поле... Ты каждый день идешь по минному полю, в-о-о-т.

Прослушав несколько первых фраз ответа интервьюируемого, респондент Б сам остановил проигрывание видеозаписи, посчитав, видимо, что его знания позволяют указать на релевантное для анализа действие, которое исследователь в силу недостатка практического опыта не смог бы идентифицировать. Ниже приведен отрывок из транскрипта исследовательского интервью с респондентом Б, соответствующий обсуждению рассматриваемого эпизода:

Респондент Б: Смотрите, уходит от ответа.

13 По всей видимости, с точки зрения журналистов, правила затрагивают не только крупных бизнесменов, но и другие категории российского истеблишмента, о чем говорит использованный респондентом термин «правила тусовки». Однако в соответствии с материалом, которым мы располагаем, мы будем говорить о правилах, действующих для представителей крупного бизнеса. 
Исследователь: Почему он уходит от ответа?

РБ: Ну, «минное поле», какие-то метафоры лишние, он не отвечает на прямо поставленный вопрос, он объясняет метафорой конкретно поставленный вопрос. Его спрашивают - кто заказал? А он... Понятно, что он и не ответит, но нам именно это и нужно.

И: Почему понятно?

РБ: Ну, потому что он знает, скорее всего, кто заказал, потому что он вторично так и говорит, что «бизнес - это игра», и он знает ее правила, и он как бы нам дает понять, что он понимает, но не может ответить, поэтому он вводит метафору.

И: А почему он не может ответить?

РБ: Ну, потому что, во-первых, это бизнес-риски и, может, даже юридические риски. Бизнес-риски в том смысле, что к нему придут тогда и скажут: «Ты чего? Мы же не собирались с тобой этого делать, тогда давай это...».

Респондент обращает внимание исследователя на то, что интервьюируемый уходит от ответа. Объясняя, почему, располагая необходимой информацией (ср. его высказывание «он знает, скорее всего, кто заказал»), гость программы предпочитает ее не раскрывать, респондент, как и его коллега до этого, указывает на некие правила, ограничивающие возможность публичных высказываний интервьюируемого. С точки зрения респондента, бизнесмен сам косвенно указывает на эти правила («он вторично так и говорит, что “бизнес - это игра”, и он знает ее правила, и он как бы нам дает понять»).

Второй вывод, который может быть сделан на основе разбора интеракции, заключается в том, что не все сказанное гостем принимается интервьюерами в качестве валидного ответа, придающего определенность интересующему их событию. Категория «уход от ответа», применяемая журналистом для оценки высказывания гостя, обозначает, что полученный от интервьюируемого вербальный ответ не способствует производству факта, а указывает на то, что «публицизация» запрашиваемой информации ограничена действием правил, несоблюдение которых может повлечь применение негативных санкций.

Эпизод 3. Вернемся к телеинтервью и перейдем к третьему эпизоду. На видеозаписи интервьюируемый продолжает формулировать ответ, журналисты при этом задают ряд дополнительных вопросов, высказывают свои предположения. Соответствующий отрывок из транскрипта телеинтервью приведен ниже:

Интервьюируемый: ...и когда мы [...], получив месторождение, еще взяли в миноритарные партнеры «Лукойл», ну чтобы быстрее начать добычу [...], как вы понимаете, это явно, что может кому-то не нравиться. И явно, так сказать, есть люди, которым это точно может не нравиться, вот.

Ведущий: А что это за люди, например?

ИЙ: Ну, а это носит разве принципиальный характер?

Интервьюеры (вместе): Да. 
ИР1: Ну, вот посмотрите, если я правильно понимаю, где-то по соседству находятся месторождения, которые принадлежат «Роснефти». И, ну, это из сферы «может быть, а может и нет», из сферы мифологии...

Ий: Все! [вскидывая руки]. Сразу! Сразу вам скажу! Сразу вам скажу на этот счет. Ну, по большому счету, конечно, я понимаю, что мы в данном случае по разные стороны баррикады, но мне точно не хочется придавать этому вариант публичности скандала...

Респондент Б снова приостанавливает проигрывание видеозаписи. На видео интервьюируемый жестом прерывает задающего вопрос журналиста. Ниже приведен транскрипт обсуждения этого эпизода:

Исследователь: Что произошло? Он прерывает вопрос?

Респондент Б: Да! Жестами! Как только слышит слово «Роснефть». Мы считываем, что «ага, значит все понятно, что, скорее всего, речь о том, что он испытывает давление со стороны структур "Роснефти"». Скорее всего, дело инспирировано, ну, как мы предполагаем, структурами «Роснефти». Но, видимо, ему не хочется заходить на поле этого разговора. [...] Потому что те десять олигархов, которые есть у нас - они в принципе не говорят. Вот редкий случай, и он является исключением, и он говорит: «Ребята, я и так вам говорю много, давайте вы меня не будете сталкивать в пропасть, над которой я стою. Поэтому давайте, вот... Вы же понимаете игру, что вот это - уже слишком». Он нас останавливает.

И: А где? Я не увидел здесь открытости.

РБ: Это нужно иметь опыт говорения с другими. Язык был бы еще более... На полюсе максимальной открытости играют те, кому нечего сказать. Есть такие балаболы, например, которые могут говорить бесконечно, их слова будут сотрясением воздуха, с них ничего нельзя будет считать.

И: Получается, задача - считать? А считать что?

РБ: Конечно! Считать какой-то другой смысл, который вкладывается в его слова, в данном случае я делаю вывод, что... «0! Мы задали правильный вопрос, и мы получили на самом деле на него ответ».

И: А как вы его получили?

РБ: «Я об этом не буду говорить» - это на самом деле ответ. Мы исходим из того, что из нашего опыта общения мы знаем, что мы [прямой] ответ скорее всего не получим. Но его реакция является ответом.

И: То есть даже не ожидая получить [ответ] «да», вы все равно задаете этот вопрос, потому что есть какие-то другие формы...

РБ: ...ответа, да. И получения информации.

И: Объясните, например, что тут...

РБ: Мне кажется, что жест.

И: А если бы это было не так, как бы он себя повел? 
РБ: Я думаю - спокойнее, он бы нас не останавливал и начал бы перечислять факты... Его попытка закрыть дискуссию говорит о значимости этой темы для него. Если бы она была не значима, он бы просто либо не реагировал бы на нее эмоционально, либо реагировал бы фактологично.

Если в предыдущих примерах интервьюеры формулировали открытые вопросы (например, «Кто за этим стоит?»), то в приведенном эпизоде вопрос журналиста уже содержит конкретные предположения по поводу обсуждаемого события. Это имеет важные последствия для процесса установления факта. С точки зрения респондента, прерывая с экспрессией задающего вопрос журналиста, интервьюируемый дает понять, что высказанные журналистом предположения затрагивают информацию, разглашение которой ограничено правилами. Это в свою очередь позволяет делать вывод о правдоподобности самих высказываемых предположений и расценивать реакцию интервьюируемого как косвенное подтверждение их обоснованности.

Третья сцена обсуждения видеозаписи позволяет, таким образом, идентифицировать еще один метод получения информации от интервьюируемого, который можно обозначить как «непрямой». Выше было сказано, что базовым методом производства фактов в процессе интервью может считаться получение прямого ответа от интервьюируемого. Однако даже при отсутствии такого ответа интервьюеры могут формировать представление об обсуждаемом событии, если вопрос был достаточно конкретен (то есть если в нем содержались определенные предположения относительно устанавливаемого события) и на некотором этапе восприятия этого вопроса гость программы проявил признаки эмоциональной реакции.

Эпизод 4. Обратимся к заключительному четвертому эпизоду рассматриваемого фрагмента телеинтервью. После серии уточнений один из журналистов ставит вопрос еще более узко. 0н предлагает конкретную кандидатуру на роль недоброжелателя гостя программы. Соответствующий отрывок из транскрипта телеинтервью приведен ниже:

Интервьюируемый: [...] по той простой причине, что я абсолютно уверен, что мы эту ситуацию..., найдем ее разрешение. Потому что, ну, много поводов, начиная от депутата ЛДПР, абсолютно надуманных [...].

Интервьюер 2: Но это гринмейл ${ }^{14}$ ?

Ий: Это... да у нас каждый день гринмейл. Поэтому, понимаете, вы, может быть, это обостреннее воспринимаете, а я воспринимаю как нормальный элемент, чтобы постоянно адреналин вырабатывался [...].

Ведущий: Если почитать российскую прессу, то там есть инсинуации или предположения, что все это, может быть, все организовано в интересах Игоря Ивановича Сечина.

ИЙ: Вы знаете, ну, поймите простую вещь... Ваша ж задача, так сказать, помочь, помочь вы мне сейчас ничем не можете...

${ }^{14}$ От англ. greenmail - термин, обозначающий корпоративный шантаж. 
ИР2: Наша задача выяснить правду.

ИР3: Разобраться.

Ий: А! Выяснить правду? Делайте собственное журналистское расследование, я только вам скажу: «Да» [...].

Во время обсуждения этого эпизода мы предложили респонденту А объяснить логику развития вопросов в рамках одного тематического блока. Дело в том, что характер вопросов демонстрирует определенную закономерность, согласно которой сначала следуют открытые вопросы, а предположения и гипотезы вводятся постепенно, ближе к концу обсуждаемой темы. Ниже приведен соответствующий отрывок из транскрипта исследовательского интервью с респондентом А, в котором он объясняет принцип организации вопросов:

Исследователь: Наконец, вот фамилия прозвучала. То есть мы видим некую сценарность в интервью. Начинаете издалека, потом...

Респондент А: Это же ничто не обговаривалось заранее. Но в своих интервью, действуя тет-а-тет, мы бы действовали примерно так же...

И: Как?

PA: Так, как действовали. Задали бы вопрос издалека и пытались бы определить, как это может развиваться.

И: А почему такая стратегия? Почему нельзя сразу сказать: «У вас проблемы, у компании, наверное, мы думаем, за этим стоит такой-то?»

PA: Ну, с тем же успехом можно сказать: «Скажите “да" или “нет"?» Он скажет: «Нет». Ну, и пошли дальше. И никому не понятно, что имелось в виду. Это не дает человеку ответить. Потому что если ты задаешь «да/нет»-вопрос, ты просто сужаешь поле, он тебе говорит «нет» и все. А здесь в конце концов зритель понимает: «Да, наверное, это Сечин». Смотрите, как человек постепенно соглашается, соглашается. Смотрите, даже сейчас прямой вопрос, и он не может ответить: «Да нет, ну что вы!». Зритель же все равно понимает.

И: Как?

PA: По всему тому, как шел этот разговор, это язык жестов, это его паузы, это... в конце концов он скажет: «Да нет, бросьте!». Вот смотрите, он не смотрит ни на [ведущего программы Тихона] Дзядко, ни на кого-либо. Он прикрыл глаза, чтобы пригасить реакцию. Он не отвечает сразу: «Да вы что! Как вы могли подумать?!» 0н начинает с некоего захода, это уже его признание.

Оценивая ответ интервьюируемого, респондент призывает не ограничиваться рассмотрением высказываний гостя, а обращать внимание на его эмоциональные реакции, жесты и позу. В случае, если в вопросе содержатся некоторые предположения относительно обстоятельств обсуждаемого события, наблюдение за этими признаками позволяет сделать вывод об их обоснованности даже при отсутствии прямого вербального подтверждения со стороны интервьюируемого. 
Как и его коллега в предыдущем примере, респондент объясняет исследователю принципы «непрямого» метода продуцирования фактов на интервью. Однако здесь содержится одно важное дополнение: респондент указывает на публичный характер этого метода. Если в предыдущей сцене респондент отмечал, что отслеживать телесные реакции интервьюируемого важно для журналистов, то в настоящей сцене респондент включает в рассмотрение аудиторию (ср.: «зритель же все равно понимает») и отмечает, что в результате такого метода детали события приобретают определенность и для публики, а не только для профессиональных журналистов. Это позволяет рассматривать «непрямой» метод производства фактов на интервью в одном ряду с методом прямого проговаривания интервьюируемым ${ }^{15}$.

Пояснения двух интервьюеров во многом совпали, несмотря на то, что журналисты представляли разные СМИ. В ситуации выяснения инициаторов давления на компанию приглашенного бизнесмена оба интервьюера указали на трудности использования прямого метода производства фактов. Причина этому, по их мнению, в том, что интервьюируемый подчиняется некоторым правилам, нормативному порядку, ограничивающему возможность высказываний в публичном пространстве. Соблюдение правил гарантируется угрозой применения негативных санкций. Одно из правил было эксплицировано более подробно. Оно касается ограничения возможности публичного обличения связанных с государством лиц, инициирующих действия агрессивного характера в отношении компании бизнесмена. В контексте процедуры производства фактов на интервью представление о наличии негласных правил, ограничивающих возможность публичных высказываний интервьюируемых, открывает для журналистов возможность «непрямого» способа производства фактов. Суть его заключается в том, что эмоциональная реакция интервьюируемого на вопрос может расцениваться (как журналистами, так и публикой) как подтверждение высказанных предположений даже при отсутствии прямого вербального подтверждения со стороны гостя программы.

Анализ организации взаимодействия журналистов и гостя программы в контексте телевизионного интервью и прояснение некоторых представлений журналистов о взаимоотношениях крупного бизнеса и власти в России позволяют сделать следующее предположение по поводу вопроса о том, почему поведение интервьюируемого могло быть расценено зрителем как невыполнение своей роли. Самоограничение гостя программы, идентифицированное зрителем в комментарии, может быть связано с наличием некоторого имперсонального нормативного порядка, действующего для крупных предпринимателей и ограничивающего возможность их высказываний в публичном пространстве. Этот нормативный порядок является имплицитным и непубличным и может быть неизвестен зрителям, далеким от сферы крупного бизнеса.

15 Тем не менее мы не ставим знака равенства между двумя этими методами. Факты, производимые ими, имеют разные сферы распространения. «Непрямой» метод производит очевидность только для тех, кто непосредственно наблюдает за сценой интервью. Проговоренная же информация может выходить за рамки интервью, она проще поддается деконтекстуализации и вследствие этого сфера ее распространения намного шире (Lauerbach and Fetzer 2007). 


\section{НОРМАТИВНЫЙ ПОРЯДОК КАК СРЕДСТВО ИНТЕРПРЕТАЦИИ И ОРГАНИЗАЦИИ ДЕЙСТВИЙ}

Жак Шаррон обращает внимание на то, что в контексте взаимодействия журналиста и источника не следует представлять ситуацию так, будто деятельность журналиста состоит в «извлечении» информации из ньюсмейкера, как будто она уже содержится в нем в готовом виде. Шаррон говорит про «взаимную подстройку путем предвосхищения», предполагая, что новость это не только продукт столкновения двух раз- личных логик (прессы и источника); каждая сторона интегрирует в некоторой степени в своей собственной логике логику другой стороны (Charron 1995:80). Применение этой идеи в контексте изучения интервью позволяет понять, что интеракционная роль интервьюера не сводится к «выуживанию» информации из интервьюируемого, она включает в себя активное сопроизводство этой информации.

В предыдущей части мы остановились на методах производства фактов на интервью в том виде, в котором они представлялись журналистам. Важным основанием этих методов являлось представление о наличии некоторого нормативного порядка или набора правил, влияющих на высказывания гостя в публичном пространстве. Нормативный порядок представлялся журналистам объективным и обоснованным возможностью применения санкций. Журналисты демонстрировали умение видеть воплощение этого порядка в действиях интервьюируемого и, соответственно, объяснять эти действия, опираясь на нормативный порядок как на объяснительный ресурс. Использованный нами метод не только обеспечил доступ к суждениям журналистов о действиях интервьюируемого, отсылающим к знанию нормативного порядка, но и дал возможность наблюдать за тем, каким образом эти суждения производились в ситуации просмотра видеозаписи и как они соотносились с действиями участников интервью на экране. Благодаря этому появляется возможность изучить некоторые аспекты интерпретационной деятельности журналистов в ситуации исследовательского интервью и предположить, каким образом эта деятельность может оказывать влияние на ход реального телевизионного интервью. Отметим дополнительно, что мы не будем стремиться поставить под сомнение достоверность интерпретаций журналистов. Цель анализа организации интерпретационного процесса состоит не в релятивизации его результатов, а в установлении механизмов его функционирования и специфики основанной на нем деятельности (Terzi 2010).

\section{МОДЕЛЬ ПОВЕДЕНИЯ АКТОРА И МЕХАНИЗМ ПРИДАНИЯ СМЫСЛА ДЕЙСТВИЯМ}

Изучая то, как респондент разбирал первый эпизод телеинтервью, можно заметить, что еще до просмотра ответа интервьюируемого журналист имел представление о том, как гость будет отвечать. Бернар Конэйн поясняет, что предсказывать поведения актора - значит приписывать его действиям мотив (Conein 1990). Выявленные фоновые представления журналистов дают нам возможность утверждать, что мотивом, который позволил респонденту прогнозировать действия интервьюируемого, являлось приписываемое ему стремление не разглашать 
информацию, подпадающую под действие правил. Знание нормативного порядка, таким образом, позволяло респонденту строить модель поведения интервьюируемого как производящего осмысленные рациональные действия.

Эта модель давала возможность не только предугадывать будущие действия интервьюируемого, но и интерпретировать уже совершенные. Во второй сцене анализа фрагмента видеозаписи программы респондент, прослушав часть ответа интервьюируемого, квалифицировал действие последнего как «уход от ответа». Для объяснения своей оценки респондент указал на некоторые элементы высказывания интервьюируемого, пояснив, что они не соответствовали прямому ответу («ну, “минное поле”, какие-то метафоры лишние, он не отвечает на прямо поставленный вопрос»). Однако, как несложно убедиться, само по себе такое объяснение, отталкивающееся от формальных свойств высказывания интервьюируемого, выглядит тавтологичным («это не прямой ответ, потому что это не прямой ответ») и явно недостаточным для понимания самого механизма интерпретации. Между тем возможность восприятия значения объекта предопределяется не только свойствами самого объекта, но и готовностью субъекта воспринимать его в таком качестве, так что вместе они формируют систему (Gibson 1979). Готовность респондента воспринимать действия интервьюируемого как «уход от ответа» обеспечивается в нашем случае не только некоторыми особенностями поведения интервьюируемого (формальными свойствами его высказываний), но и наличием под рукой у респондента основанной на знании нормативного порядка модели действия актора. Именно она позволяла квалифицировать «уход от ответа» интервьюируемого не только как возможное, но и как вполне ожидаемое действие (на это указал сам респондент: «Понятно, что он не ответит»).

Первый важный вывод, таким образом, заключается в том, что знание о правилах, ограничивающих возможность высказываний интервьюируемого в публичном пространстве, является для журналистов не просто некоторым безучастным отражением действительности. Это знание «деятельно» уже хотя бы потому, что особым образом структурирует для журналистов их интеракционное окружение на интервью, позволяя оценивать действия гостя программы определенным образом.

\section{ОСНОВАНИЯ МЕХАНИЗМА ПРОИЗВОДСТВА ФАКТОВ}

Каким образом представление журналистов о том, что на гостя программы действуют правила, участвует в процессе интеракционного производства фактов во время интервью? Как было сказано выше, журналисты располагают «непрямым» методом производства фактов. Суть метода в том, что если вопрос снабжен предположениями относительно некоторого события и в определенный момент восприятия вопроса интервьюируемый демонстрирует эмоциональную реакцию, то эта реакция может расцениваться журналистами как подтверждение заложенных в вопрос предположений. Проблема такого метода заключается в том, что «эмоциональность» является не объективным свойством поведения интервьюируемого (так называемым буквальным описанием (literal description) этого поведения, говоря языком Томаса Уилсона (Wilson 1970)), а значением, которое приписывается поведению интервьюируемого в определенном контексте. 
Отсылка к эмоциональному поведению в той или иной форме возникала в сценах анализа третьего и четвертого эпизодов фрагмента телеинтервью. Вернемся к этим сценам, чтобы понять контекст, в котором эта категория использовалась респондентами. Напомним, что в исходном телеинтервью к этому моменту в разговор уже были введены конкретные предположения по поводу личностей тех, кто стал причиной проблем в бизнесе героя. Разбирая третий эпизод, респондент пытался спрогнозировать, как бы вел себя интервьюируемый, если бы озвученное журналистами предположение не соответствовало действительности: «Я думаю - спокойнее, он бы нас не останавливал и начал бы перечислять факты... Его попытка закрыть дискуссию говорит о значимости этой темы для него. Если бы она была не значима, он бы просто [...] не реагировал бы на нее эмоционально». Анализируя четвертый эпизод, респондент объяснял, как зритель может сделать вывод об обоснованности предположений журналистов: «Вот смотрите, он не смотрит ни на [ведущего программы Тихона] Дзядко, ни на кого-либо, он прикрыл глаза, чтобы пригасить реакцию, он не отвечает сразу: “Да вы что! Как вы могли подумать!”. Он начинает с некоего захода, это уже его признание». Рено Дюлон (Dulong 1997) предлагает различать, с одной стороны, ситуации, в которых некоторый объект (в рассматриваемом нами случае это наблюдаемое телесное поведение интервьюируемого) непосредственно и дорефлексивно приводит к ощущению очевидности определенного положения дел (тогда об объекте уместно говорить как об «операторе фактуальности»), и, с другой стороны, ситуации, когда тот же самый объект используется для обоснования или доказательства истинности определенного представления положения дел другому человеку. Две эти ситуации, пусть и связанные друг с другом, предполагают различные «регистры рациональности». Нетрудно понять, что процитированные выше пояснения респондентов, в которых использовалась категория «эмоциональный», относятся ко второй группе ситуаций - к группе ситуаций убеждения, предполагающей выстраивание аргументации и предоставление доказательств. Если же мы перенесемся в регистр рациональности, характерный для первого охарактеризованного Дюлоном типа ситуаций (когда наблюдение за телесным поведением человека, выступающим в качестве оператора фактуальности, непосредственно и дорефлексивно приводит к ощущению очевидности события, восстановить которое пытаются журналисты), то более важным будет не вопрос, является ли тот или иной жест эмоциональным, а вопрос, почему эмоциональное поведение интервьюируемого вообще может иметь какое-либо отношение к статусу высказываемых журналистами предположений. Чтобы ответить на этот вопрос, напомним, что, согласно представлениям журналистов, поведение крупного бизнесмена в публичном пространстве ограничено негласными правилами, а несоблюдение этих правил влечет за собой риск применения негативных санкций. Это позволяет журналистам полагать, что ситуация интервью, особенно в момент потенциальной возможности «публицизации» сведений, на которые распространяется действие правил, представляется для интервьюируемого ситуацией высокого риска, требующей внутреннего напряжения и самоконтроля, различные проявления которых могут становиться видимыми. Это, в свою очередь, привлекает дополнительное внимание к телесным реакциям интервьюируемого. Описанное отношение к телесному поведению интервьюируемого, 
делает возможным регистр доказательства и аргументации, где отдельные жесты и телодвижения могут быть изолированы и предъявлены сомневающемуся в качестве «эмоциональной реакции».

Таким образом, роль представлений о наличии правил как основы интерпретационного процесса, осуществляемого журналистами, оказывается еще более важной. Эти представления не только форматируют интеракционное окружение журналистов, заставляя оценивать ответы гостя в определенном ключе, но и участвуют в процедуре производства фактов, приводя к тому, что теперь не только слова, но и особенности невербального поведения гостя программы могут становиться операторами фактуальности событий.

\section{ВОПЛОЩЕННОСТЬ НОРМАТИВНОГО ПОРЯДКА В ЖУРНАЛИСТСКИХ ПРАКТИКАХ}

Обратимся теперь к тому, как представления о нормативном порядке проявляются в действиях журналистов. Располагая моделью поведения актора, основанной на знании нормативного порядка, журналисты воспринимают интервью иначе, чем это делал бы не обладающий такими фоновыми представлениями обыватель. Сказанное интервьюируемым утрачивает для них значение непосредственного отражения действительности. Обсуждая третий эпизод видеофрагмента интервью, респондент указывает, что задача, стоящая перед журналистами, - «считать какой-то другой смысл, который вкладывается в его слова». «Непрямой» метод производства фактов выходит здесь на первый план. Журналисты воспринимают подтверждение своих предположений посредством анализа поведения интервьюируемого уже не как некоторый побочный продукт интервьюирования, а как одну из основных целей подобного рода интеракции. Во время разбора третьего эпизода фрагмента интервью, например, респондент подтвердил, что, задавая некоторые вопросы, журналисты не ожидают получить от интервьюируемого полный прямой ответ («из нашего опыта общения мы знаем, что мы [прямой] ответ, скорее всего, не получим»). Однако журналисты все равно задают эти вопросы, так как существуют «другие формы получения информации», к которым относится, например, эмоциональная реакция интервьюируемого.

Более того, журналисты не только пассивно считывают то, что становится для них признаками эмоциональной реакции интервьюируемого, но и активно участвуют в их сопроизводстве. В этом можно убедиться, если обратиться к четвертой сцене анализа видеофрагмента, где рассматривается особая форма упорядочивания вопросов. В рамках одного тематического блока вопросы распределяются так, что сначала следуют наиболее общие и открытые вопросы, а предположения и детали, которые известны журналистам из других источников, вводятся постепенно. Это заставляет гостя программы многократно отвечать на один и тот же вопрос, который по мере развития темы несколько раз меняет форму, обрастая новыми подробностями и предположениями. Такой способ организации вопросов физически заставляет интервьюируемого совершать большее количество различных жестов и телодвижений, которые, как было показано выше, могут приобретать для журналистов и аудитории особое качество операторов фактуальности событий. 
Таким образом, представления о нормативном порядке подталкивают журналистов к особой организации процесса интеракции, направленной в некоторых случаях не столько на получение вербальных ответов, сколько на «провоцирование» видимых телесных реакций и жестов, часть которых можно трактовать как ответ на вопросы журналистов.

Стремясь прояснить основания и механизмы интерпретационной и практической деятельности журналистов на интервью, мы установили, что важным компонентом этой деятельности оказалась вера в существование правил, которые влияют на действия гостя программы. Проявления этого влияния обнаруживались журналистами в конкретных действиях интервьюируемого. Такую особенность перцептивной деятельности акторов исследователи называют «спонтанным эмпиризмом» (Barthélémy 1990). Под этим понимается распространенное убеждение акторов в том, что их знание об объекте детерминировано идентичностью самого объекта, притом что конституирующие его как объект знания социальные практики (включающие веру в существование нормативного порядка) не замечаются. «Незамечаемость» социальной работы по приписыванию значений явлениям социального мира составляет между тем одно из условий поддержания объективности социальной реальности. Действительно, в результате просмотра телеинтервью зритель воспринял уклончивость интервьюируемого не как продукт интеракции в целом, а как объективное свойство поведения гостя программы. Мы же постарались показать, что отдельную роль в этом впечатлении могут играть и сами журналисты, которые, обладая определенными фоновыми представлениями относительно поведения интервьюируемого, предполагая и предвосхищая его уклончивость, строят взаимодействие таким образом, что невольно подчеркивают или даже производят ее посредством самой драматургии интервью.

В нашем изложении нормативный порядок может показаться конструктом журналистов, а уклончивость интервьюируемого - исключительно продуктом искаженного понимания журналистами реальности и отражения этого понимания в действиях. Поэтому в заключение нам следует предостеречь читателя от такого радикального прочтения наших аргументов. Если мы и считаем, что восприятие реальности осуществляется акторами посредством социальных категорий, то мы ни в коей мере не хотим при этом сказать, что эти категории являются полностью искусственными и ни на чем не основанными. В этом отношении наша позиция близка тому, что Сириль Лемьё (Lemieux 2012) определяет как «рефлексивный конструктивизм». Такой подход, с одной стороны, предполагает, что все категории, используемые акторами, являются социально произведенными, но, с другой стороны, принимает позицию, согласно которой коллективные концепции реальности не являются абсолютно произвольными и никак не связанными с миром, который пытаются постичь, но, напротив, несут в себе следы постоянного столкновения с материальностью этого мира в практической деятельности. Нормативный порядок, оказавшийся в центре нашего рассмотрения, не является, таким образом, неким заблуждением или иллюзией журналистов. Напротив, повседневно сталкиваясь с его проявлениями, журна- 
листы имеют все основания верить в его объективность. Конструктом может являться выбираемая ими форма концептуализации явления, с которым они сталкиваются, но, выражаясь фигурально, не само сопротивление, которое они ощущают при столкновении.

\section{ЗАКЛЮЧЕНИЕ}

Вернемся к вопросу о том, почему договор между зрителем и программой оказался нарушен, а интервьюируемый не продемонстрировал ожидаемой искренности? Наше исследование не претендует на то, чтобы исчерпывающе ответить на этот вопрос, но некоторые ответы оно способно предложить. Мы указали на наличие некоторого непубличного и имперсонального нормативного порядка, действующего для крупных бизнесменов и ограничивающего возможность их публичных высказываний в отношении высокопоставленных представителей государственной власти и близких к ним акторов. Далее мы обратили внимание на коллективный процесс поддержания веры в существование этого нормативного порядка, в который включены и сами журналисты, неосознанно, а потому еще более эффективно актуализирующие его и способствующие проявлению его эффектов в ситуации интервью.

Претензия зрителя по поводу выступления интервьюируемого изначально была представлена нами как признак некоторого отклонения или нерегулярности. Но частота, с которой публичные выступления российских крупных предпринимателей оцениваются схожим образом, заставляет задуматься о значении этих оценок как самостоятельного систематического явления. Обратим внимание на то, что объектом зрительской критики становится интервьюируемый, а не нормативный порядок или роль журналистов в интеракционной актуализации этого нормативного порядка. Говоря о политических дебатах кандидатов в президенты, Патрик Шампань писал, что «принцип большинства эффектов, которые они производят, лежит в общей вере в то, что они производят эффекты» (Champagne 1989:14), иными словами - в вере в то, что дебаты позволяют объективно оценить кандидатов. Аналогичным образом вера зрителя в то, что телеинтервью позволяет увидеть и оценить личные качества гостя, притом что социальный и интеракционный контексты этой демонстрации остаются незамеченными, становится одним из условий коллективного процесса реификации подчинения крупных бизнесменов высокопоставленным представителям государственной власти, которое теперь, благодаря работе журналистов, не только становится очевидным, но и лишается своей коллективно-нормативной природы, приобретая невынужденный и персональный характер. В этом плане символично, что комментарий, послуживший отправной точкой для нашего исследования, появился на экране в определенный момент интервью. Представляя собой реакцию одного из зрителей, этот комментарий в то же время оказывается интегральной частью программы, становясь одновременно и вердиктом интервьюируемому, и инструкцией по оценке его выступления для других телезрителей. 


\section{СПИСОК ЛИТЕРАТУРЫ}

Болтански, Люк и Лоран Тевено. [1991] 2013. Критика и обоснование справедливости: очерки социологии градов. М.: Новое литературное обозрение.

Паппэ, Яков и Яна Галухина. 2009. Российский крупный бизнес. М.: Издательский дом ВШЭ.

Barthe, Yannick, Damien De Blic, Jean-Philippe Heurtin, Éric Lagneau, Cyril Lemieux, Dominique Linhardt, Cédric Bellaing, Catherine Rémy, and Danny Trom. 2013. "Sociologie pragmatique: Mode d'emploi." Politix 3(103):175-204.

Barthélémy, Michel. 1990. "Voir et dire l'action: La normalisation des comportements des jeunes autistes." Pp. 195-226 in Les formes de l'action, edited by Louis Quéré and Patrick Pharo. Paris: Éditions de l'École des hautes études en sciences sociales.

Bovet, Alain, and Cédric Terzi. 2011. “Montrer et accomplir l'ordre politique: Ethnographie d'un débat à la télévision Suisse romande." Pp. 231-255 in Du civil au politique: Ethnographies du vivre-ensemble, edited by Mathieu Berger, Daniel Cefaï, and Carole Gayet-Viaud. Brussels: Peter Lang.

Bull, Peter, and Kate Mayer. 1993. "How Not to Answer Questions in Political Interviews." Political Psychology 14(4):651-666.

Cefaï, Daniel, and Dominique Pasquier. 2003. “Introduction." Pp. 13-59 in Le sens du public: Publics politiques, publics médiatiques, edited by Daniel Cefaï and Dominique Pasquier. Paris: Presses universitaires de France.

Champagne, Patrick. 1989. “Qui a gagné? Analyse interne et analyse externe des débats politiques à la télévision." Mots 20:5-22.

Charron, Jean. 1995. “Les médias et les sources: Les limites du modèle de l'agenda-setting." Hermès 3(17-18):73-92.

Chupin, Ivan, and Jérémie Nollet. 2006. “Jalons pour une sociologie historique des interdépendances du journalisme à d'autres univers sociaux." Pp. 15-36 in Journalisme et dépendances, edited by Ivan Chupin and Jérémie Nollet. Paris: L'Harmattan.

Clayman, Steven E. 2001. "Answers and Evasions." Language in Society 30(3):403-442.

Clayman, Steven E., and John Heritage. 2002. The News Interview: Journalists and Public Figures on the Air. Cambridge: Cambridge University Press.

Clayman, Steven E., John Heritage, Marc N. Elliott, and Laurie L. McDonald. 2007. "When Does the Watchdog Bark? Conditions of Aggressive Questioning in Presidential News Conferences." American Sociological Review 72(1):23-41.

Conein, Bernard. 1990. “Peut-on observer l'interprétation? Daniel Dennett et l'éthologie cognitive." Pp. 311-334 in Les formes de l'action, edited by Louis Quéré and Patrick Pharo. Paris: Éditions de l'École des hautes études en sciences sociales.

Dayan, Daniel. 1992. “Les mystères de la réception." Le débat 4(71):141-157.

Dayan, Daniel, and Elihu Katz. 1992. Media Events: The Live Broadcasting of History. Cambridge, MA: Harvard University Press.

Désert, Myriam. 2010. “Les entrepreneurs et la régulation économique." Pp. 253-262 in La Russie contemporaine, edited by Gilles Favarel-Garrigues and Kathy Rousselet. Paris: Fayard.

Dulong, Renaud. 1997. "Les opérateurs de factualité: Les ingrédients matériels et affectuels de l'évidence historique." Politix 10(39):65-85.

Ekström, Mats. 2001. “Politicians Interviewed on Television News." Discourse \& Society 12(5):563-584.

Ekström, Mats, and Åsa Kroon Lundell. 2009. “The News Interview: Diversity and Hybridity in the Communicative Activities of Broadcast News." Paper presented at the 19th Nordic Conference for Media and Communication Research, August 13-15, Karlstad, Sweden.

Emerson, Robert M. 1981. “Observational Field Work." Annual Review of Sociology 7:351-378.

Fetzer, Anita, and Elda Weizman. 2006. "Political Discourse as Mediated and Public Discourse." Journal of Pragmatics 38(2):143-153.

Gans, Herbert J. 1979. Deciding What's News: A Study of CBS Evening News, NBC Nightly News, Newsweek, and Time. New York: Pantheon Books. 
Gibson, James. 1979. The Ecological Approach to Visual Perception. Boston: Houghton Mifflin. Greatbatch, David. 1988. "A Turn-Taking System for British News Interviews." Language in Society 17(3):401-430.

Guriev, Sergei, and Andrei Rachinsky. 2005. “The Role of Oligarchs in Russian Capitalism." Journal of Economic Perspectives 19(1):131-150.

Hall, Stuart. [1973] 1980. “Encoding, Decoding." Pp. 128-138 in Culture, Media, Language, edited by Stuart Hall, Dorothy Hobson, Andrew Love, and Paul Willis. London: Hutchinson.

Harris, Sandra. 1991. "Evasive Action: How Politicians Respond to Questions in Political Interviews." Pp. 76-99 in Broadcast Talk, edited by Paddy Scannell. London: Routledge.

Hutchby, Ian. 2006. Media Talk: Conversation Analysis and the Study of Broadcasting. Maidenhead, UK: Open University Press.

Kaciaf, Nicolas. 2007. “'́objectivation du rapport aux sources dans les pages 'Politiques' des quotidiens." Pp. 227-250 in Les publics des journalistes, edited by Jean-Baptiste Legavre and Pascal Dauvin. Paris: La Dispute.

Lauerbach, Gerda, and Anita Fetzer. 2007. “Political Discourse in the Media: Cross-Cultural Perspectives." Pp. 3-28 in Political Discourse in the Media, edited by Anita Fetzer and Gerda Eva Lauerbach. Amsterdam: John Benjamins Publishing Company.

Legavre, Jean-Baptiste. 2011. "Entre conflit et coopération: Les journalistes et les communicants comme 'associés-rivaux."' Communication \& Langages 167:105-123.

Lemieux, Cyril. 2012. “Peut-on ne pas être constructiviste?" Politix 4(100):169-187.

Livingstone, Sonia, and Peter Lunt. 1994. Talk On Television: Audience Participation and Public Debate. London: Routledge.

Molotch, Harvey, and Marilyn Lester. 1974. "News as Purposive Behavior: On the Strategic Use of Routine Events, Accidents, and Scandals." American Sociological Review 39(1):101-112.

Montgomery, Martin. 2008. "The Discourse of the Broadcast News Interview: A Typology." Journalism Studies 9(2):260-277.

Morley, David. 1980. The "Nationwide" Audience. London: British Film Institute.

Neveu, Érik. 1989. “'L'heure de vérité' ou Le triangle de la représentation." Mots 20:57-73.

Neveu, Érik. 1995. "Les émissions politiques à la télévision: Les années quatre-vingt ou les impasses du spectacle politique." Hermès 3(17-18):145-162.

Schlesinger, Philip. 1978. Putting "Reality" Together: BBC News. London: Constable and Company Limited.

Schudson, Michael. 1994. "Question Authority: A History of the News Interview in American Journalism, 1860s-1930s." Media, Culture \& Society 16(4):565-587.

Shoemaker, Pamela J., and Stephen D. Reese. 1996. Mediating the Message: Theories of Influences on Mass Media Content. New York: Longman.

Sigal, Leon V. 1973. Reporters and Officials: The Organization and Politics of Newsmaking. Lexington, MA: D. C. Heath.

Sigal, Leon V. 1986. "Who? Sources Make the News." Pp. 9-37 in Reading the News, edited by Robert Karl Manoff and Michael Schudson. New York: Pantheon Books.

Terzi, Cédric. 2010. "L'art de la respécification ethnométhodologique." Pp. 169-181 in L'engagement ethnographique, edited by Daniel Cefaï. Paris: Éditions de l'École des hautes études en sciences sociales.

Tuchman, Gaye. 1978. Making News: A Study in the Construction of Reality. New York: Free Press.

Wilson, Thomas P. 1970. "Conceptions of Interaction and Forms of Sociological Explanation." American Sociological Review 35(4):697-710.

Zimmerman, Don H. 1974. "Fact as a Practical Accomplishment." Pp. 128-143 in Ethnomethodology, edited by Roy Turner. Middlesex, UK: Penguin Education. 


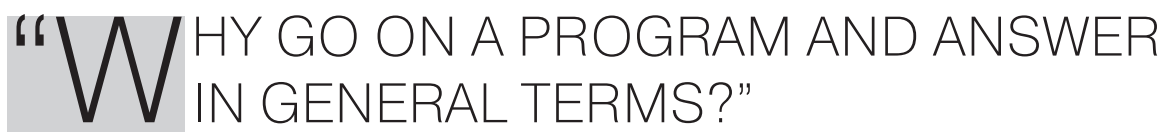 TV INTERVIEWS AS A MECHANISM FOR THE REPRODUCTION OF THE POLITICAL ORDER}

\section{Alexander Lutsenko}

Alexander Lutsenko is a PhD student at the Interdisciplinary Laboratory for the Study of Reflexivities (LIER), Marcel Mauss Institute, School for Advanced Studies in the Social Sciences (Paris). Address for correspondence: 10 Rue Monsieur Le Prince, 75006, Paris, France. a.loutsenko@yahoo.fr.

This article explores the phenomenon of broadcast interviews with the owners of large Russian businesses. Using the example of Hard Day's Night, an interview program on the private television channel Dozhd', the article takes audience complaints about the interviewees' evasiveness as a starting point for a discussion about the role that broadcast interviews play in maintaining political order. The argument unfolds in three steps. Firstly, on the basis of research interviews with channel staff and video analysis of the program, I establish a participation framework of the interview, allowing for the elucidation of the specific obligations the interviewee fails to fulfill. Secondly, I study in detail the interactional organization of the interview, using an original method of analyzing video clips alongside the hosts of the program. I identify a set of implicit impersonal rules that guide what the owners of big Russian businesses can say publicly about high-ranking state officials. Finally, the article focuses on the interactional role that journalists play in the organization of the interview by using these rules as a background scheme for their actions. I conclude that the viewers' and journalists' belief that the interviews provide an opportunity to demonstrate the individual qualities of the interviewee, while the social and interactional contexts of this demonstration go unnoticed, contributes to the reification of the submission of the owners of large Russian businesses to high-ranking state officials.

Keywords: Broadcast Interviews; Businessmen; Journalists; Engagement Contract;

Production of Facts; Rules; Nonverbal Reactions; Political Order

\section{REFERENCES}

Barthe, Yannick, Damien De Blic, Jean-Philippe Heurtin, Éric Lagneau, Cyril Lemieux, Dominique Linhardt, Cédric Bellaing, Catherine Rémy, and Danny Trom. 2013. "Sociologie pragmatique: Mode d'emploi." Politix 3(103):175-204.

Barthélémy, Michel. 1990. "Voir et dire l'action: La normalisation des comportements des jeunes autistes." Pp. 195-226 in Les formes de l'action, edited by Louis Quéré and Patrick Pharo. Paris: Éditions de l'École des hautes études en sciences sociales.

Boltanski, Luc, and Laurent Thévenot. [1991] 2013. Kritika i obosnovanie spravedlivosti: Ocherki sotsiologii gradov. Moscow: Novoe literaturnoe obozrenie.

Bovet, Alain, and Cédric Terzi. 2011. “Montrer et accomplir l'ordre politique: Ethnographie d'un débat à la télévision Suisse romande." Pp. 231-255 in Du civil au politique: Ethnographies du vivreensemble, edited by Mathieu Berger, Daniel Cefaï, and Carole Gayet-Viaud. Brussels: Peter Lang. 
Bull, Peter, and Kate Mayer. 1993. "How Not to Answer Questions in Political Interviews." Political Psychology 14(4):651-666.

Cefaï, Daniel, and Dominique Pasquier. 2003. “Introduction." Pp. 13-59 in Le sens du public: Publics politiques, publics médiatiques, edited by Daniel Cefaï and Dominique Pasquier. Paris: Presses universitaires de France.

Champagne, Patrick. 1989. “Qui a gagné? Analyse interne et analyse externe des débats politiques à la télévision." Mots 20:5-22.

Charron, Jean. 1995. “Les médias et les sources: Les limites du modèle de l'agenda-setting." Hermès 3(17-18):73-92.

Chupin, Ivan, and Jérémie Nollet. 2006. “Jalons pour une sociologie historique des interdépendances du journalisme à d'autres univers sociaux." Pp. 15-36 in Journalisme et dépendances, edited by Ivan Chupin and Jérémie Nollet. Paris: L'Harmattan.

Clayman, Steven E. 2001. “Answers and Evasions." Language in Society 30(3):403-442.

Clayman, Steven E., and John Heritage. 2002. The News Interview: Journalists and Public Figures on the Air. Cambridge: Cambridge University Press.

Clayman, Steven E., John Heritage, Marc N. Elliott, and Laurie L. McDonald. 2007. "When Does the Watchdog Bark? Conditions of Aggressive Questioning in Presidential News Conferences." American Sociological Review 72(1):23-41.

Conein, Bernard. 1990. “Peut-on observer l'interprétation? Daniel Dennett et l'éthologie cognitive." Pp. 311-334 in Les formes de l'action, edited by Louis Quéré and Patrick Pharo. Paris: Éditions de l'École des hautes études en sciences sociales.

Dayan, Daniel. 1992. “Les mystères de la réception." Le débat 4(71):141-157.

Dayan, Daniel, and Elihu Katz. 1992. Media Events: The Live Broadcasting of History. Cambridge, MA: Harvard University Press.

Désert, Myriam. 2010. “Les entrepreneurs et la régulation économique." Pp. 253-262 in La Russie contemporaine, edited by Gilles Favarel-Garrigues and Kathy Rousselet. Paris: Fayard.

Dulong, Renaud. 1997. "Les opérateurs de factualité: Les ingrédients matériels et affectuels de l'évidence historique." Politix 10(39):65-85.

Ekström, Mats. 2001. “Politicians Interviewed on Television News." Discourse \& Society 12(5):563584.

Ekström, Mats, and Åsa Kroon Lundell. 2009. “The News Interview: Diversity and Hybridity in the Communicative Activities of Broadcast News." Paper presented at the 19th Nordic Conference for Media and Communication Research, August 13-15, Karlstad, Sweden.

Emerson, Robert M. 1981. “Observational Field Work." Annual Review of Sociology 7:351-378.

Fetzer, Anita, and Elda Weizman. 2006. "Political Discourse as Mediated and Public Discourse." Journal of Pragmatics 38(2):143-153.

Gans, Herbert J. 1979. Deciding What's News: A Study of CBS Evening News, NBC Nightly News, Newsweek, and Time. New York: Pantheon Books.

Gibson, James. 1979. The Ecological Approach to Visual Perception. Boston: Houghton Mifflin.

Greatbatch, David. 1988. "A Turn-Taking System for British News Interviews." Language in Society 17(3):401-430.

Guriev, Sergei, and Andrei Rachinsky. 2005. "The Role of Oligarchs in Russian Capitalism." Journal of Economic Perspectives 19(1):131-150.

Hall, Stuart. [1973] 1980. “Encoding, Decoding." Pp. 128-138 in Culture, Media, Language, edited by Stuart Hall, Dorothy Hobson, Andrew Love, and Paul Willis. London: Hutchinson.

Harris, Sandra. 1991. "Evasive Action: How Politicians Respond to Questions in Political Interviews." Pp. 76-99 in Broadcast Talk, edited by Paddy Scannell. London: Routledge.

Hutchby, Ian. 2006. Media Talk: Conversation Analysis and the Study of Broadcasting. Maidenhead, UK: Open University Press.

Kaciaf, Nicolas. 2007. “L'objectivation du rapport aux sources dans les pages 'Politiques' des quotidiens." Pp. 227-250 in Les publics des journalistes, edited by Jean-Baptiste Legavre and Pascal Dauvin. Paris: La Dispute. 
Lauerbach, Gerda, and Anita Fetzer. 2007. “Political Discourse in the Media: Cross-Cultural Perspectives." Pp. 3-28 in Political Discourse in the Media, edited by Anita Fetzer and Gerda Eva Lauerbach. Amsterdam: John Benjamins Publishing Company.

Legavre, Jean-Baptiste. 2011. “Entre conflit et coopération: Les journalistes et les communicants comme 'associés-rivaux."' Communication \& Langages 167:105-123.

Lemieux, Cyril. 2012. “Peut-on ne pas être constructiviste?" Politix 4(100):169-187.

Livingstone, Sonia, and Peter Lunt. 1994. Talk On Television: Audience Participation and Public Debate. London: Routledge.

Molotch, Harvey, and Marilyn Lester. 1974. “News as Purposive Behavior: On the Strategic Use of Routine Events, Accidents, and Scandals." American Sociological Review 39(1):101-112.

Montgomery, Martin. 2008. "The Discourse of the Broadcast News Interview: A Typology." Journalism Studies 9(2):260-277.

Morley, David. 1980. The "Nationwide" Audience. London: British Film Institute.

Neveu, Érik. 1989. “'L'heure de vérité' ou Le triangle de la représentation." Mots 20:57-73.

Neveu, Érik. 1995. "Les émissions politiques à la télévision: Les années quatre-vingt ou les impasses du spectacle politique." Hermès 3(17-18):145-162.

Pappe, Iakov, and Iana Galukhina. 2009. Rossiiskii krupnyi biznes. Moscow: Izdatel'skii dom GU VShE.

Schlesinger, Philip. 1978. Putting "Reality" Together: BBC News. London: Constable and Company Limited.

Schudson, Michael. 1994. "Question Authority: A History of the News Interview in American Journalism, 1860s-1930s." Media, Culture \& Society 16(4):565-587.

Shoemaker, Pamela J., and Stephen D. Reese. 1996. Mediating the Message: Theories of Influences on Mass Media Content. New York: Longman.

Sigal, Leon V. 1973. Reporters and Officials: The Organization and Politics of Newsmaking. Lexington, MA: D. C. Heath.

Sigal, Leon V. 1986. “Who? Sources Make the News." Pp. 9-37 in Reading the News, edited by Robert Karl Manoff and Michael Schudson. New York: Pantheon Books.

Terzi, Cédric. 2010. “'Lart de la respécification ethnométhodologique." Pp. 169-181 in L'engagement ethnographique, edited by Daniel Cefaï. Paris: Éditions de l'École des hautes études en sciences sociales.

Tuchman, Gaye. 1978. Making News: A Study in the Construction of Reality. New York: Free Press.

Wilson, Thomas P. 1970. “Conceptions of Interaction and Forms of Sociological Explanation." American Sociological Review 35(4):697-710.

Zimmerman, Don H. 1974. "Fact as a Practical Accomplishment." Pp. 128-143 in Ethnomethodology, edited by Roy Turner. Middlesex, UK: Penguin Education. 